\title{
Structure and functional characterization of pyruvate decarboxylase from Gluconacetobacter diazotrophicus
}

\author{
Leonardo J van Zyl $\left.\right|^{1 *}$, Wolf-Dieter Schubert ${ }^{2}$, Marla I Tuffin ${ }^{1}$ and Don A Cowan ${ }^{3}$
}

\begin{abstract}
Background: Bacterial pyruvate decarboxylases (PDC) are rare. Their role in ethanol production and in bacterially mediated ethanologenic processes has, however, ensured a continued and growing interest. PDCs from Zymomonas mobilis (ZmPDC), Zymobacter palmae (ZpPDC) and Sarcina ventriculi (SvPDC) have been characterized and ZmPDC has been produced successfully in a range of heterologous hosts. PDCs from the Acetobacteraceae and their role in metabolism have not been characterized to the same extent. Examples include Gluconobacter oxydans (GoPDC), G. diazotrophicus (GdPDC) and Acetobacter pasteutrianus (ApPDC). All of these organisms are of commercial importance.

Results: This study reports the kinetic characterization and the crystal structure of a PDC from Gluconacetobacter diazotrophicus (GdPDC). Enzyme kinetic analysis indicates a high affinity for pyruvate ( $K_{M} 0.06 \mathrm{mM}$ at $\mathrm{pH}$ 5), high catalytic efficiencies $\left(1.3 \cdot 10^{6} \mathrm{M}^{-1} \cdot \mathrm{s}^{-1}\right.$ at $\mathrm{pH}$ 5), $\mathrm{pH}_{\text {opt }}$ of 5.5 and $\mathrm{T}_{\text {opt }}$ at $45^{\circ} \mathrm{C}$. The enzyme is not thermostable $\left(\mathrm{T}_{1 / 2}\right.$ of 18 minutes at $60^{\circ} \mathrm{C}$ ) and the calculated number of bonds between monomers and dimers do not give clear indications for the relatively lower thermostability compared to other PDCs. The structure is highly similar to those described for $Z$. mobilis (ZmPDC) and A. pasteurianus PDC (ApPDC) with a rmsd value of $0.57 \AA$ for Ca when comparing GdPDC to that of ApPDC. Indole-3-pyruvate does not serve as a substrate for the enzyme. Structural differences occur in two loci, involving the regions Thr341 to Thr352 and Asn499 to Asp503.

Conclusions: This is the first study of the PDC from G. diazotrophicus (PAL5) and lays the groundwork for future research into its role in this endosymbiont. The crystal structure of GdPDC indicates the enzyme to be evolutionarily closely related to homologues from Z. mobilis and A. pasteurianus and suggests strong selective pressure to keep the enzyme characteristics in a narrow range. The $\mathrm{pH}$ optimum together with reduced thermostability likely reflect the host organisms niche and conditions under which these properties have been naturally selected for. The lack of activity on indole-3-pyruvate excludes this decarboxylase as the enzyme responsible for indole acetic acid production in G. diazotrophicus.
\end{abstract}

\section{Background}

Pyruvate decarboxylase (PDC, EC 4.1.1.1) is the enzyme responsible for the non-oxidative decarboxylation of pyruvate to acetaldehyde and carbon dioxide. All characterized PDCs are dependent on the cofactors thiamine diphosphate (ThDP) and $\mathrm{Mg}^{2+}$. A recent study proposed a PDC capable of co-factor independent decarboxylation of pyruvate [1], however this discovery has been refuted [2]. Although widespread in the plant kingdom and amongst

\footnotetext{
* Correspondence: vanzyllj@gmail.com

${ }^{1}$ Institute for Microbial Biotechnology and Metagenomics (IMBM), University of the Western Cape, Robert Sobukwe Road, Bellville, Cape Town, South Africa Full list of author information is available at the end of the article
}

ascomycetous yeasts and fungi, PDCs are comparatively rare in prokaryotes. Several of the plant and yeast PDCs have been isolated and characterized, however; by contrast only five bacterial PDCs have been described, namely those from Zymomonas mobilis (ZmPDC), Zymobacter palmae (ZpPDC), Sarcina ventriculi (SvPDC), Acetobacter pasteurianus (ApPDC) and Gluconobacter oxydans (GoPDC) [3-8].

In higher organisms and most prokaryotes (Z. mobilis, Z. palmae and S. ventriculi), the PDC forms part of the fermentative pathway leading to ethanol production. Therefore, bacterial PDCs and their hosts have been the focus of extensive characterization and engineering 
efforts to develop ethanologenic strains [7,9-15]. In the Acetobacteraceae (A. pasteurianus, and G. oxydans) however, PDC links oxidative lactate assimilation (lactate dehydrogenase; pyruvate forming) and ethanol consumption (alcohol dehydrogenase; pyruvate forming) to the production of acetate, and therefore forms part of oxidative metabolism $[4,16]$. In G. oxydans, which only has a partial TCA cycle, all L-lactate, fructose and mannitol is converted to acetate via the PDC showing its metabolic importance in this organism [16].

Although the exact mechanism of ThDP dependent decarboxylation has not yet been fully described, it centrally involves the deprotonation of atom $\mathrm{C} 2$ of the thiazolium ring to yield a corresponding carbanion or ylide [17]. The latter nucleophillically attacks the carbonyl group of pyruvate substrate to yield a $\mathrm{C} 2$ - $\alpha$-lactylthiamin diphosphate intermediate $[18,19]$. The enzymes bind ThDP in a conformation that places the N4' atom of the aminopyrimidine ring near atom $\mathrm{C} 2$. N4' is a strong base in the imino tautomeric state of the aminopyrimidine ring allowing it to deprotonate $\mathrm{C} 2$ and activate the cofactor. Glu50, within hydrogen bonding distance of N1 and deprotonated under physiological conditions, was previously thought to induce the amino to imino tautomerization of the aminopyrimidine ring [20]. More recent studies of the pre-reaction state of ZmPDC, however, suggest that Glu469 instead directly abstracts a proton from N4' [21,22]. Decarboxylation of the lactyl cofactor adduct yields an enamine/carbanion mesomeric intermediate with concomitant $\mathrm{CO}_{2}$ release. The carbanion/enamine intermediate becomes protonated to give hydroxyethyl ThDP and release of the acetaldehyde product regenerates the ylide [20,23-26]. Crystal structures for PDCs from Z. mobilis (ZmPDC) and A. pasteurianus (ApPDC) are published [27,28].

Gluconacetobacter diazotrophicus, a member of the family Acetobacteraceae, is a Gram negative, obligate aerobic bacterium. This organism is also nitrogen fixing and endophytic, setting it apart from other acetic acid bacteria. It is often found in association with sugar cane where it stimulates plant growth through the secretion of auxin-like compounds, notably indole acetic acid (IAA) $[29,30]$. No indolepyruvate decarboxylases could be identified on the G. diazotrophicus PAL5 genome sequence, however several decarboxylases were identified, one of which is possibly responsible for production of IAA from indole-3-pyruvate [31]. Of these, one showed significant sequence similarity to other true bacterial PDCs and although the role of PDC has been investigated in two other members of this family (see above), its role in this unique bacterium is not known.

As described, the enzyme fulfills multiple roles in key metabolic pathways and has potential for use in engineering of ethanologenic strains. In order to confirm the annotated sequence as a true PDC and to further elucidate the role of the enzymes in these plant-associated organisms, we kinetically characterized the PDC from G. diazotrophicus (GdPDC) and solved the GdPDC crystal structure at $1.7 \AA$, adding to our knowledge of these rare enzymes.

\section{Results}

Functional characterization of the G. diazotrophicus PDC

A search against the non-redundant NCBI database using the GdPDC protein sequence as query identified only 27 bacterial proteins $(\mathrm{E}$-value $=0)$, despite the wealth of sequence data available, including metagenomic sequences. PDCs with identity to the bacterial enzymes which have been studied and which are not of Acetobacteraceae origin are few (Figure 1). All bacterial proteins related to GdPDC that are annotated as PDCs are shown in Figure 1, and included are the indole-3-pyruvate decarboxylase from Enterobacter cloacae and the benzoyl-formate decarboxylase from Pseudomonas putida for reference, as well as the best BLAST hit against the non-redundant NCBI environmental metagenomic proteins database. The same sequences are identified when using any of the five Gram negative PDCs as search query. The proteins related to the Gram negative PDCs from bacteria other than the Acetobacteraceae include putative enzymes from the family or order: Chroococcales, Oscillatoriales (2), Alteromonadaceae, Legionellaceae (2), Chloroflexi, Acidobacteriaceae, and Beijerinckiaceae.

G. diazotrophicus pdc was amplified, cloned and sequenced. PCR amplification introduced one amino acid change, P554Q, four residues from the end of the chain. As C-terminal deletions after this position do not affect activity for ZmPDC, this substitution is not expected to affect enzyme activity substantially [34]. Of the characterized PDC's, the amino acid sequence of GdPDC is most closely related to that of $Z$. palmae PDC sharing amino acid identity of $71 \%$, followed by $70 \%$ to PDC from $A$. pasteurianus. The protein shares the typical ThDP binding motif GDGS-XXX-NN and retains conserved residues for substrate binding and catalysis (Additional file 1: Figure S1).

GdPDC was purified to homogeneity by affinity chromatography as judged by reducing SDS-PAGE analysis (Additional file 2: Figure S2). The MW of $\pm 60 \mathrm{kDa}$ corresponds well to the theoretical molecular mass of $59.2 \mathrm{kDa}$. The predicted $\mathrm{pI}$ is 5.8 . The kinetic parameters of the enzyme are summarized in Table 1 . The $K_{M}$ value for pyruvate decreased $\sim 20$-fold on decreasing the $\mathrm{pH}$ from 7 to 5 and at $\mathrm{pH} 5$ this value is twofold lower than the lowest $K_{M}$ reported for any PDC at this $\mathrm{pH}$ [7]. The catalytic rate $\left(k_{\text {cat }}\right)$ remains unaffected similar to related enzymes Table 1 [26] supporting the idea that PDC requires the de-protonation of the ThDP aminopyrimidine ring for catalysis [26]. The enzyme displays Michaelis 


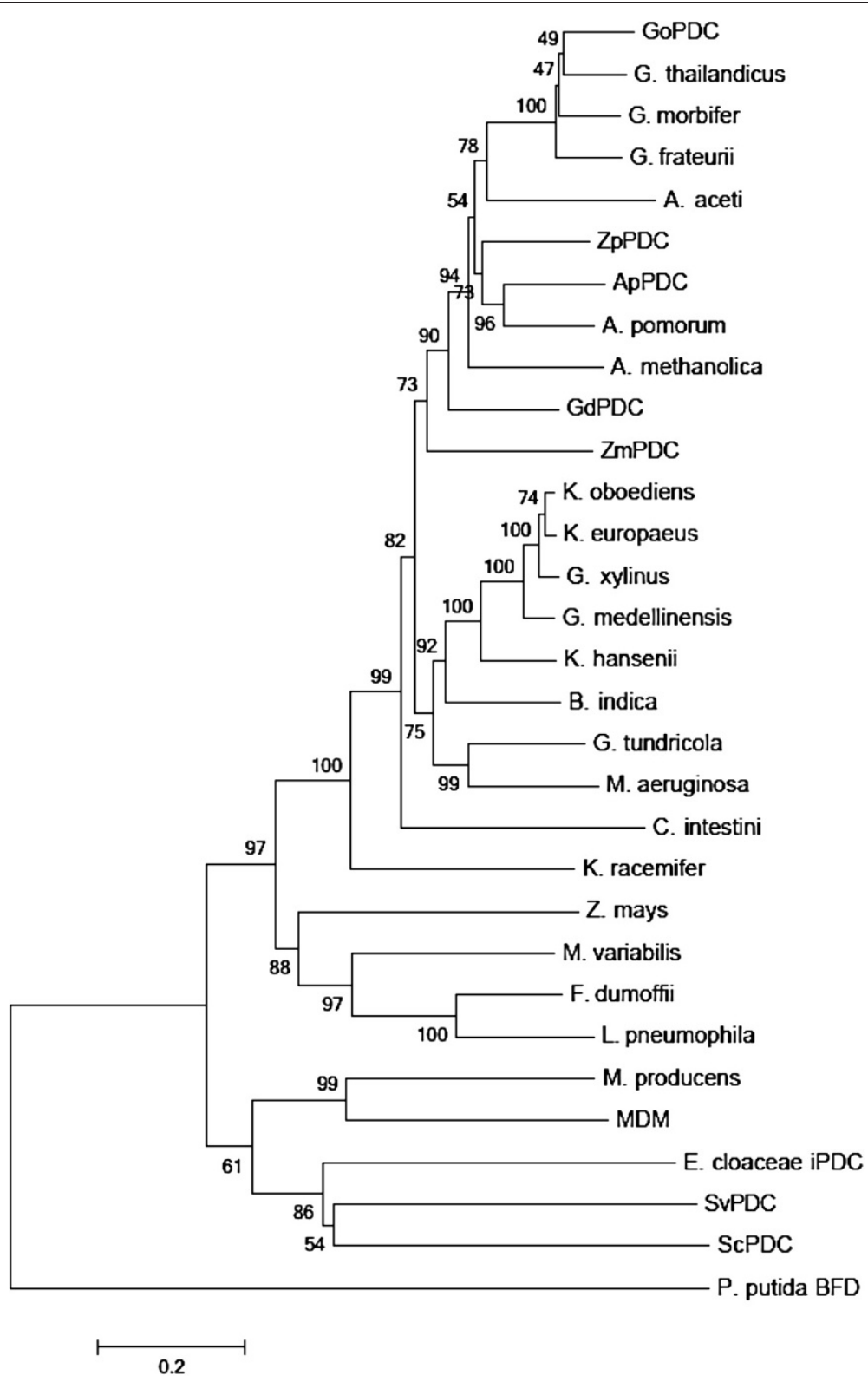

Figure 1 Neighbor-joining tree comparing full length amino acid sequences of PDC-related proteins. The optimal tree with the sum of branch length $=8.50849307$ is shown. The percentage of replicate trees in which the associated taxa clustered together in the bootstrap test (1000 replicates) is shown next to the branches [32]. The tree is drawn to scale, with branch lengths in the same units as those of the evolutionary distances used to infer the phylogenetic tree. The evolutionary distances were computed using the Poisson correction method [33] and are in the units of the number of amino acid substitutions per site (scale bar). The analysis involved 31 amino acid sequences. All ambiguous positions were removed for each sequence pair. There were a total of 633 positions in the final dataset. GdPDC - G. diazotrophicus (KJ746104); GoPDC - G. oxydans (KF650839); ApPDC Acetobacter pasteurianus (AF368435.1); ZpPDC - Z. palmae (AF474145); ZmPDC - Z. mobilis (AB359063); ZmPDC - Z. mays (X17555); ScPDC - S. cerevisiae (X04675); SVPDC - S. ventriculi (AF354297); Lyngbya aestuarii (WP023067698); Acidomonas methanolica (GAJ29946); Acetobacter pomorum (WP006115789); Acetobacter aceti (WP010667855); Microcystis aeruginosa (WP_0027648); Moorea producens (WP008180762); Microbulbifer variabilis (WP020414286); Legionella pneumophila (YP006505162); MDM (CBI10829); Ktedonobacter racemifer (WP007922190); Komagataeibacter oboediens (WP010515737); Komagataeibacter hansenii (WP003622049); Komagataeibacter europaeus (WP010509054); Granulicella tundricola (YP004210504); Gluconobacter thailandicus (WP007283613); Gluconobacter morbifer (WP008852112); Gluconobacter frateurii (WP023941876); Gluconacetobacter xylinus (AHI26557); Gluconacetobacter medellinensis (YP004868149); Fluoribacter dumoffii (WP010654974); Enterobacter cloacae iPDC (P23234); Commensalibacter intestini (WP008853550); Beijerinckia indica (YP001834435); Pseudomonas putida BFD (YP008115845) ; MDM- Mine Drainage Metagenome (CBI10829.1). 
Table 1 Characterization data (Steady state kinetic constants, $\mathrm{T}_{\mathrm{opt}}$ and $\mathrm{pH}_{\mathrm{opt}}$ ) for GdPDC using pyruvate and compared with those from other Gram negative bacteria (The values represent the average of at least two individual rounds of protein purification and assay)

\begin{tabular}{|c|c|c|c|c|c|c|}
\hline PDC & $K_{M}(\mathrm{mM})$ & Specific activity in (U/mg) & $k_{\text {cat }} / K_{M}\left(\mathrm{M}^{-1} \cdot \mathrm{s}^{-1}\right)$ & $\mathrm{T}_{\text {opt }}\left({ }^{\circ} \mathrm{C}\right)$ & $\mathrm{T}_{1 / 2}$ at ${ }^{\circ} \mathrm{C}$ & $\mathrm{pH}_{\mathrm{opt}}$ \\
\hline \multirow[t]{3}{*}{ GdPDC } & $0.06(5.0)^{*}$ & $20(5.0)$ & $1.3 \times 10^{6}(5.0)$ & $45-50$ & $18 \mathrm{~min}$ at $60^{\circ} \mathrm{C}$ & $5.0-5.5$ \\
\hline & $0.60(6.0)$ & $39(6.0)$ & $2.6 \times 10^{5}(6.0)$ & & & \\
\hline & $1.2(7.0)$ & $43(7.0)$ & $1.4 \times 10^{5}(7.0)$ & & & \\
\hline \multirow[t]{3}{*}{ GoPDC } & $0.12(5.0)[7]$ & $57(5.0)[7]$ & $1.9 \times 10^{6}(5.0)[7]$ & $53[7]$ & $10 \mathrm{~min}$ at $65^{\circ} \mathrm{C}[7]$ & $4.5-5.0[7]$ \\
\hline & $1.2(6.5)[7]$ & $47(6.5)[7]$ & $1.6 \times 10^{5}(6.5)[7]$ & & & \\
\hline & $2.8(7.0)[7]$ & $125(7.0)[7]$ & $1.8 \times 10^{5}(7.0)[7]$ & & & \\
\hline ApPDC & 2.8 (6.5) [36]/0.39 (5.0) [5] & 110 (6.5) [36]/97 (5.0) [5] & $1.3 \times 10^{6}(5.0)^{\#}[5]$ & $65[36]$ & 24 min at $70^{\circ} \mathrm{C}[36]$ & $3.5-6.5[36]$ \\
\hline ZpPDC & $2.5(6.5)[36] / 0.24(6.0)[5]$ & $116(6.5)[36] / 130(6.0)[5]$ & $1.4 \times 10^{6}(6.0)^{\#}[5]$ & $55[36]$ & 24 min at $60^{\circ} \mathrm{C}[36]$ & 7.0 [36] \\
\hline ZmPDC & $\begin{array}{l}1.3(6.5)[36] / 0.31(6.0) \\
{[26] / 1.1[37] / 0.4(6.0)[38]}\end{array}$ & $120(6.5)[36] / 120[37] / 181[38]$ & $\begin{array}{l}1.9 \times 10^{6}(6.0)[26] / 4.4 \times 10^{5} \\
(6.5)[37] / 1.79 \times 10^{6}(6.0)[38]\end{array}$ & $60[36]$ & $30 \mathrm{~min}$ at $60^{\circ} \mathrm{C}[36]$ & $6.0-6.5[36]$ \\
\hline SVPDC & $13[6]$ & $103[6]$ & $3.2 \times 10^{4}[6] / 0.87 \times 10^{4}(7.0)$ & N/A & $30 \mathrm{~min}$ at $50^{\circ} \mathrm{C}$ & $6.3-6.7[6]$ \\
\hline
\end{tabular}

Numbers after values are the references from which the numbers were obtained.

*Values in brackets indicate assay $\mathrm{pH}$.

\#Calculated based on values given in reference [5].

Menten kinetics with pyruvate as substrate and is not subject to allosteric substrate activation, as for the PDCs from plants, fungi, and the bacterium $S$. ventriculi [35]. Catalytic efficiencies were also similar to those reported for SvPDC, the only known representative from a Gram positive bacterium, and ZmPDC which is the best studied enzyme.

Its temperature optimum is between $45^{\circ} \mathrm{C}$ and $50^{\circ} \mathrm{C}$ (Figure 2A), one of the lowest for bacterial PDCs. GdPDC is less thermostable than PDCs from other Gram negative bacterial enzymes, retaining $15 \%$ activity after $30 \mathrm{~min}$ at $60^{\circ} \mathrm{C}$ (half-life of $18 \mathrm{~min}$, Figure 2B) and no residual activity after $1 \mathrm{~h}$ at $60^{\circ} \mathrm{C}$. The activation energy of GdPDC on pyruvate was determined in the linear range from $25^{\circ} \mathrm{C}$ to $45^{\circ} \mathrm{C}$ to be $46 \mathrm{~kJ} / \mathrm{mol}$, which is in agreement with values reported for other bacterial PDCs (44). The alanine, cysteine and phenylalanine content of PDCs was previously proposed to correlate with its thermostability [5]. Alanines constitute $17 \%$ of the residues in GdPDC (Cys 1.6\%, Phe $2.5 \%)$ but $12 \%$ in GoPDC (2\%, 3\%), $15 \%$ in ZmPDC $(1.2 \%$, $3.1 \%), 13 \%$ in ZpPDC $(1.8 \%, 2.7 \%), 13 \%$ in ApPDC (2\%, $2.5 \%)$ and $6.9 \%$ in SvPDC $(0.9 \%, 4.7 \%)$. Despite having the highest alanine content of all the bacterial PDCs, GdPDC is not the most thermostable, contradicting amino acidbased predictions [5]. Other factors might contribute to the lower in vitro thermostability of GdPDC observed

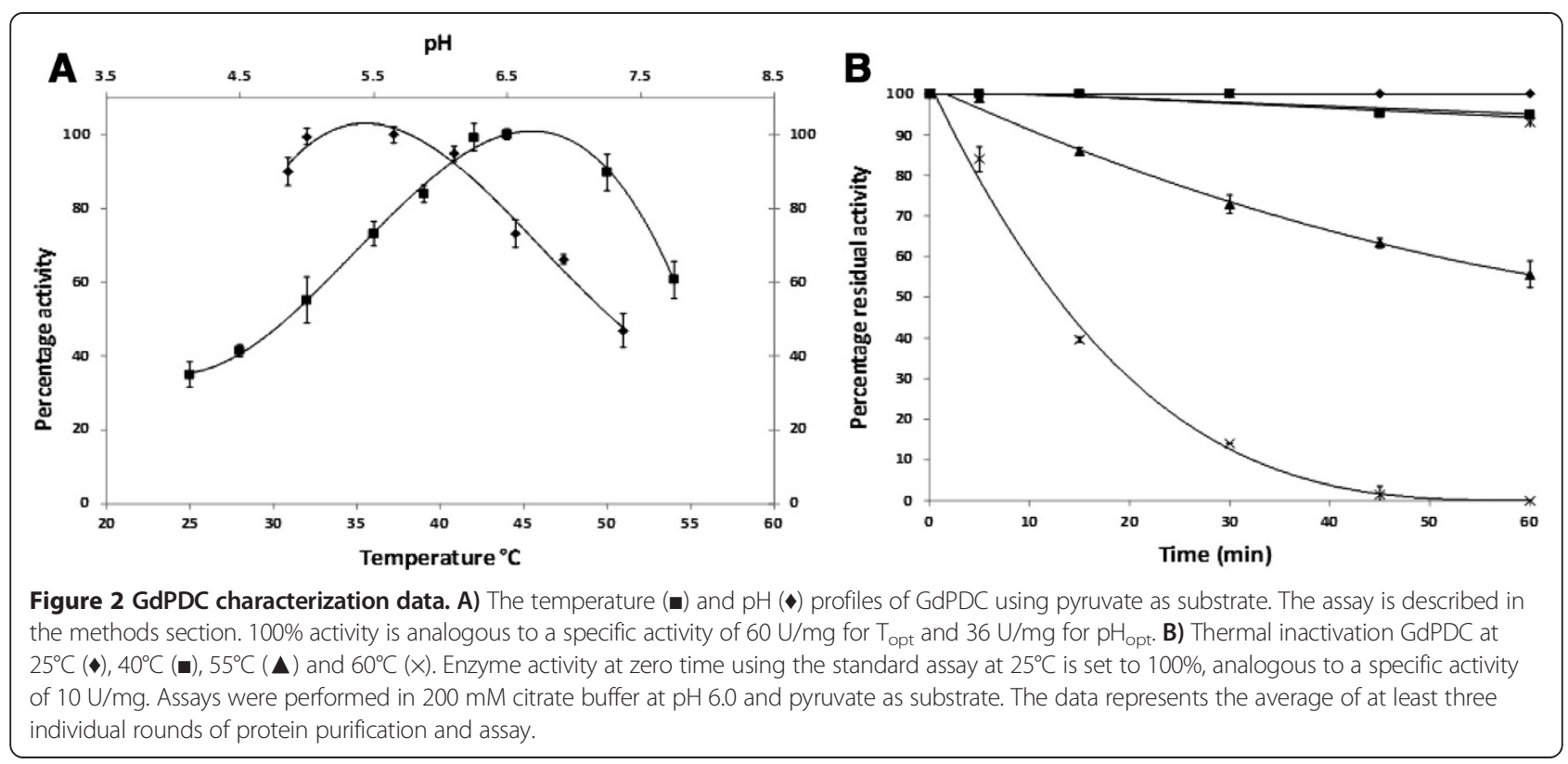


here, as has been summarized in a comparative study conducted by Pohl and coworkers [39]. For example, the use of $\mathrm{MgCl}_{2}$ instead of $\mathrm{MgSO}_{4}$ to provide the $\mathrm{Mg}^{2+}$ cofactor may affect thermostability as the sulfate anion is known to stabilize PDC enzymes [39].

GdPDC was assayed using a range of substrates including 2-ketopropanoate (pyruvate), 2-ketobutanoate, 2-ketopentanoate, 2-keto-4-methylpentanoate, 3-phenyl2-oxopropanoate, benzoyl formate, 3-hydroxy-phenyl pyruvate and indole-3-pyruvate. Specific activities for substrates 2-ketobutanoate (12 U/mg), 2-ketopentanoate $(0.68 \mathrm{U} / \mathrm{mg})$ and 2-keto-4-methylpentanoate $(0.15 \mathrm{U} / \mathrm{mg})$, respectively at $24 \mathrm{mM}$, are similar to those previously reported for other bacterial PDC's [36,37]. Activities for benzoyl formate, 3-hydroxy-phenyl pyruvate and indole-3-pyruvate, if present, were below detection limits.

\section{G. diazotrophicus PDC crystal structure}

GdPDC crystallized in the monoclinic space group $\mathrm{C} 2$ with cell dimensions: $\mathrm{a}=129.1 \AA \mathrm{A}, \mathrm{b}=141.0 \AA \mathrm{A}, \mathrm{c}=91.1 \AA$, $\beta=125.8^{\circ}$, with two monomers per asymmetric unit (Table 2; Additional file 3: Figure S3). The crystal structure of the G. diazotrophicus PDC was solved by molecular replacement using a side-chain cropped dimer of the $A$. pasteurianus PDC (2VBI) as a search model. The high resolution diffraction data (Table 2) and the good quality of the electron density distribution allowed for facile model building for the major part of the protein (see Methods) and most residues are well-defined.

Table 2 Statistics for data collection, processing and the final model of the GdPDC crystal structure

\begin{tabular}{|c|c|}
\hline \multicolumn{2}{|l|}{ Statistics of data collection } \\
\hline Resolution $(\AA)^{*}$ & $30.0-1.69(1.78-1.69)$ \\
\hline Wavelength $(\AA ̊)$ (synchrotron and station) & 0.980 (SOLEIL Proxima 1) \\
\hline Total number of reflections* & 435137 (61046) \\
\hline Total number of unique reflections* & $146264(21363)$ \\
\hline Multiplicity* & $3.0(2.9)$ \\
\hline$R_{\text {merge }}{ }^{*}$ & $0.080(0.299)$ \\
\hline $1 / s d(I)^{*}$ & $8.8(3.3)$ \\
\hline Completeness (\%)* & $99.4(99.6)$ \\
\hline \multicolumn{2}{|c|}{ Statistics of refinement and the final model } \\
\hline Resolution $(\AA)$ & $84.06-1.69$ \\
\hline Number of reflections & 138948 \\
\hline$R_{\text {free }}$ & 0.158 \\
\hline$R_{\text {work }}$ & 0.127 \\
\hline $\begin{array}{l}\text { rmsd [bond lengths }(\AA) / \text { bond } \\
\left.\text { angles }\left({ }^{\circ}\right) / \text { chiral volume }\left(A^{3}\right)\right]\end{array}$ & $0.033 / 2.48 / 0.235$ \\
\hline $\begin{array}{l}\text { Ramachandran plot } \\
\text { (preferred/allowed/outlier) (\%) }\end{array}$ & $98.1 / 1.5 / 0.4$ \\
\hline$B_{\text {mean }}$ of all atoms $\left(\AA^{2}\right)$ & 14.8 \\
\hline
\end{tabular}

*Values in brackets indicate the shell of highest resolution.
The quaternary structure of GdPDC is a homo-tetramer best described as a dimer of dimers (Figure 3A) as for $\mathrm{ZmPDC}$ and ApPDC. The tetramer is generated by applying a crystallographic 2 -fold symmetry to the noncrystallographic dimer in the asymmetric unit. The accessible surface area of the monomer-monomer interface amounts to $3740 \AA^{2}$, somewhat smaller than the $4150 \AA^{2}$ for ZmPDC [27] but similar to that of ApPDC $\left(3770 \AA^{2}\right)$. The surface area between the dimers of the tetramer is $2738 \AA^{2}$ for GdPDC, $3784 \AA^{2}$ for ZmPDC and $3812 \AA^{2}$ for ApPDC. GdPDC has 63 hydrogen bonds between monomers, fewer than the 76 for ZmPDC but more than the 60 of ApPDC. Thirteen salt bridges support the monomer-monomer interface (ZmPDC 14, ApPDC 16). There is significantly less hydrogen bonding between dimers which make up a tetramer at 44 compared with ZmPDC-70 and ApaPDC-74, while the number of salt bridges also shows some variation with GdPDC having 26, ZmoPDC-20 and ApaPDC-28.

The refined crystal structure contains two identical chains of 544 amino acids (residues 2-180, 191-555), each binding a ThDP cofactor and $\mathrm{Mg}^{2+}$ ion. The model contains 1167 water molecules. The rmsd for C $\alpha$ atoms of the two monomers in the asymmetric unit is only $0.088 \AA$ indicating a very high similarity and correspondingly a negligible effect of inter-monomer or crystal packing forces. As for other PDCs, each protein monomer may be thought of consisting of three distinct structural domains: the pyrimidine binding (PYR, residues 1-186), the regulatory $(\mathrm{R}, 187-349)$ and the pyrophosphate binding (PP, 350-558) domains. The rmsd between $\mathrm{C} \alpha$ atoms of GdPDC and ApPDC is $0.57 \AA$ implying largely similar structures.

As mentioned, GdPDC demonstrated Michaelis Menten kinetics. Two residues, Tyr157 and Arg224, were shown to be involved in binding a second molecule of the substrate analogue pyruvamide in Saccharomyces cerevisiae PDC (ScPDC), and are conserved in SvPDC; both enzymes display substrate activation [35,40]. Arg224 (Arg221 in GdPDC and ZmPDC) is conserved in a range of PDC-like enzymes based on structure- and sequence-based alignments (Figure 4B and Additional file 1: Figure S1), however Tyr157 is not and appears to be unique to the enzymes showing substrate activation.

One of two ThDP molecules in the GdPDC structure appears to be modified as also reported for the ZmPDC, based on weak electron density for the $\mathrm{C} 2$ carbon atom of the thiazolium ring. As for $\mathrm{ZmPDC}$, degradation of the cofactor presumably occurs after crystallization [27]; Figure 3B.

Residues 104-113 together with residues 290-304, in the structure of ScPDC (1PYD), are presumably involved in closing the active site during catalysis, as they are disordered, but adopt a stable conformation upon binding 


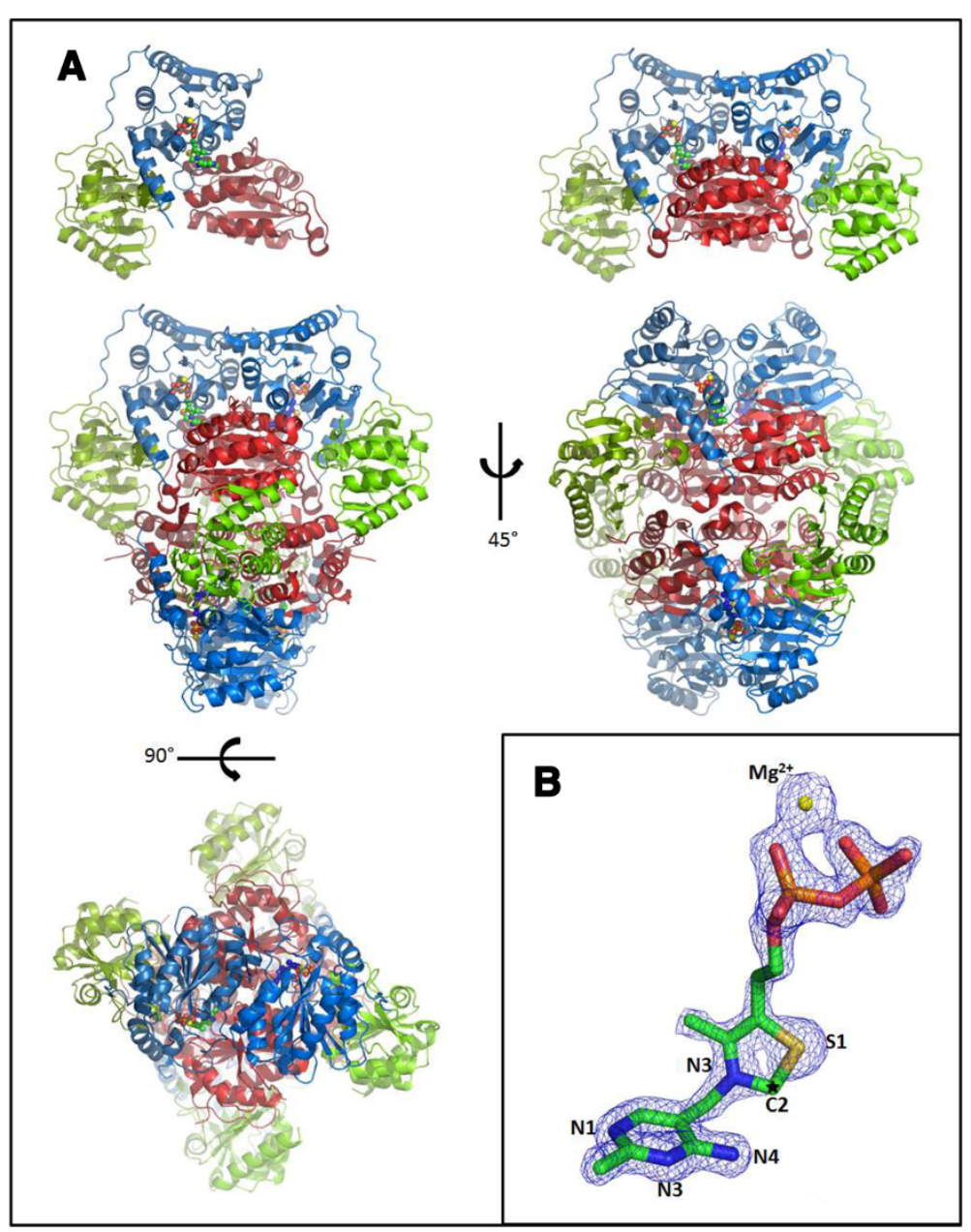

Figure 3 Tertiary and quarternary structure of GdPDC. A) A cartoon representation of GdPDC structure monomer (left) and dimer (right) showing the PYR-domain in red, PP-domain in blue and the R-domain in green. ThDP and $\mathrm{Mg}^{2+}$ are shown as space fill models. B) $2 F_{o}-F_{c}$ electron density map (blue, contoured at 2.0 б) for ThDP. The lack of electron density for the C2 position of the thiazole ring may indicate the loss of this atom.

the substrate analogue pyruvamide (1QPB) [41,42]. In GdPDC these residues are well defined in the electron density map despite the absence of substrate, also as reported for ZmPDC. This may be due to stabilizing interactions with residues of the $\mathrm{R}$ - and PP-domains (N288, D289, Q407 and R553). Binding of the inactive ThDP triazole ring analogue and pyruvate induce dramatic conformational changes in ZmPDC [21]. Similar conformational changes would presumably also occur in GdPDC as this region is structurally highly conserved in bacterial PDCs (Figure 4C). A "water tunnel" links the two active sites (Figure 5) presumably to serve as a proton relay system as previously suggested for ZmPDC and the E1 subunit of PDHc [22,43].

Apart from differences in amino acid sequence, ZmPDC and GdPDC differ structurally in several areas (Figure 4A). In ZmPDC a loop of five amino acids (Asn499-Asp503) in the PP-domain extends toward the PP-domain of the second subunit creating a number of stabilizing interactions in particular through Tyr502 ${ }^{\mathrm{A}}$ (in monomer A). Tyr502 ${ }^{\mathrm{A}}$ intercalates between Tyr $468^{\mathrm{B}}$ and Phe538 involving extensive $\pi-\pi$ stacking interactions to the former and van der Waals interactions to the latter. In addition, Tyr502 ${ }^{\mathrm{A}}$ forms a C-H... $\pi$ interaction to Asn $466^{B}$ and a hydrogen bond between its $\mathrm{OH}$ group and both $\mathrm{Asn} 466^{\mathrm{B}}-\mathrm{O}$ and Ile $539^{\mathrm{B}}-\mathrm{N}$, as well as a hydrogen bond between its mainchain $\mathrm{N}$ and $\mathrm{Asn} 486^{\mathrm{B}}-\mathrm{O}_{\delta 1}$. Further interactions include a hydrogen bond from Asp503 ${ }^{\mathrm{A}}$ to $\mathrm{Tyr} 468^{\mathrm{B}}$ and a salt bridge between $\mathrm{Asp} 503^{\mathrm{A}}$ and Lys485 ${ }^{\mathrm{B}}$. In GdPDC this loop is shorter by four amino acids, foregoing all the described stabilizing interactions, possibly contributing to the lower thermal stability of this protein. Interestingly, the situation in GdPDC is similar to that in ApPDC (2VBI), which displays higher thermostability (Table 1).

A second region which is clearly different involves the 11 residues linking the PP- and R-domains in GdPDC (residues Thr341 to Thr352, Figure 4A). This stretch is clearly defined in all three structures, however the 


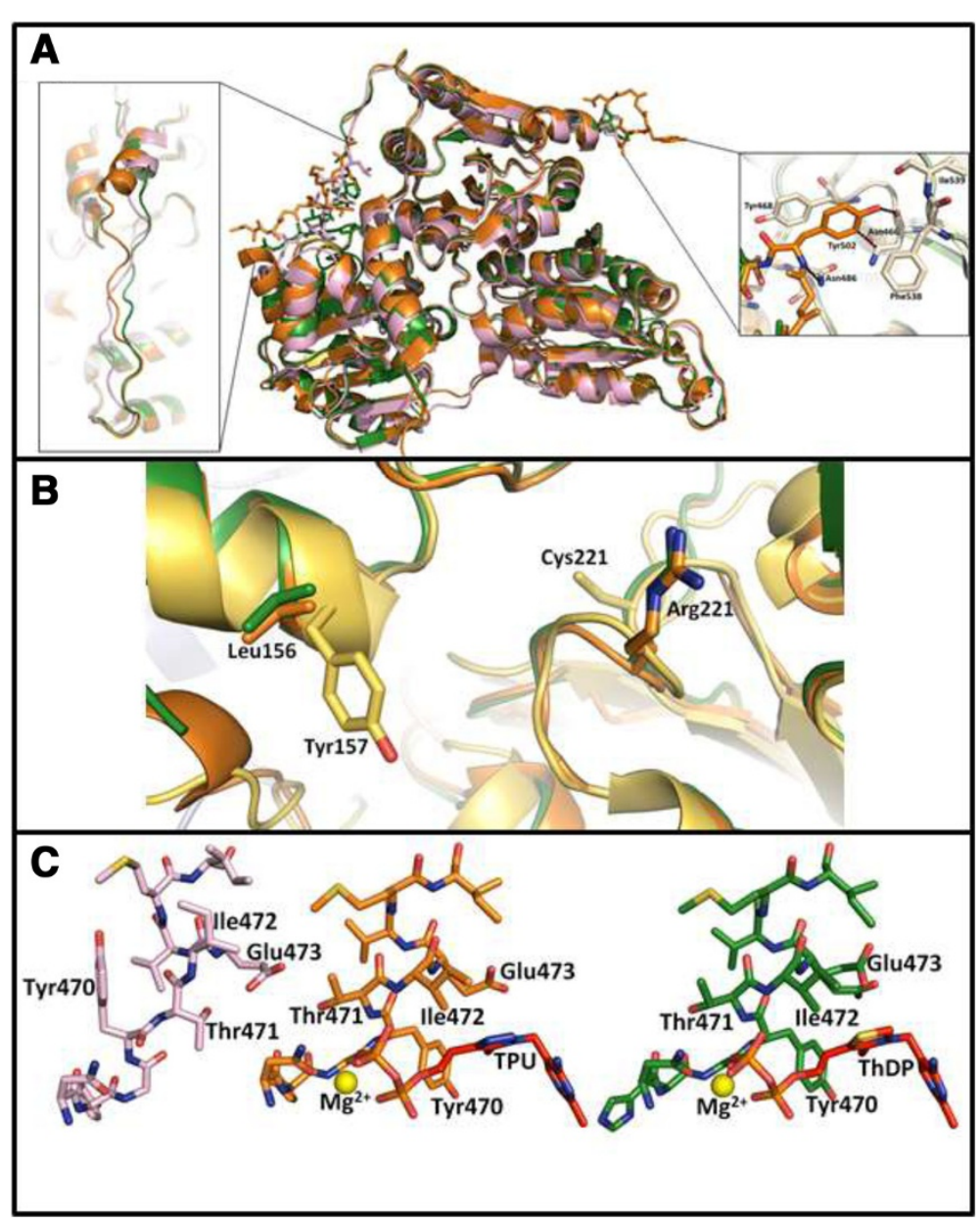

Figure 4 Conformational differences between ZmPDC, ApPDC and GdPDC. A) Superposition of ZmPDC (orange), ApPDC (pink) and GdPDC (green) monomers emphasizing two regions where their conformations differ. Deviating regions are shown as stick models, conserved regions as ribbon diagrams. They extend from T341 to T352 and N499 to D503. Left insert: linker region, right insert: Interactions of Tyr502 B) An alignment of SCPDC (1QPD, yellow), ZmPDC (1ZPD, orange) and GdPDC (4COK, green) showing conserved residues, Arg221, Cys221, Tyr157 and Leu156 on either side of the cleft between PYR and R-domains. Arg221 is conserved but adopts a different conformation in ScPDC compared to ZmPDC and GdPDC. Tyr157 is unique to SCPDC, replaced by Leu156 in the bacterial homologues. Bacterial enzymes lack Cys221, involved in substrate induced allosteric activation in ScPDC C) Conformational change brought about by ThDP cofactor binding. Left to right: apo-ZmPDC (2WVH, pink), ZmPDC, TPU (2WVG, orange) and GdPDC, ThDP (4COK, green).

positioning of this region differs substantially between the three structures implying unique stabilization details in each. The linker can thus potentially affect both enzyme stability and activity, but in a more subtle way.

The linker connecting the R- and PYR-domains of GdPDC (residues 184-191) is not defined in the electron density of both symmetrically independent monomers implying it to be highly disordered. The corresponding residues have therefore not been included in the final model. In crystal structures of ZmPDC and ApPDC these residues are well defined and are stabilized through contacts to other residues in the R-and PYR-domains clearly stabilizing the linker region. Interestingly this seven-residue linker contains three proline residues which likely add rigidity to the region [44]. However, proline has been shown to be one of the preferred amino acids in domain linker regions, and they are thought to structurally isolate the linker from the protein domains as they have no hydrogen bond to donate, perhaps, as in this case, leading to a flexible linker rather than one rigidified by the proline residues $[45,46]$. Disorder in flexible regions of other PDCs (ScPDC) has been linked to a physiological role, and disorder in linker regions of proteins often indicates a physiological significance $[47,48]$.

\section{Discussion}

We have characterized the sixth bacterial PDC, from the acetic acid bacterium G. diazotrophicus, and solved its resting state structure. Our analysis indicates the substrate range of the enzyme to be similar to that of 


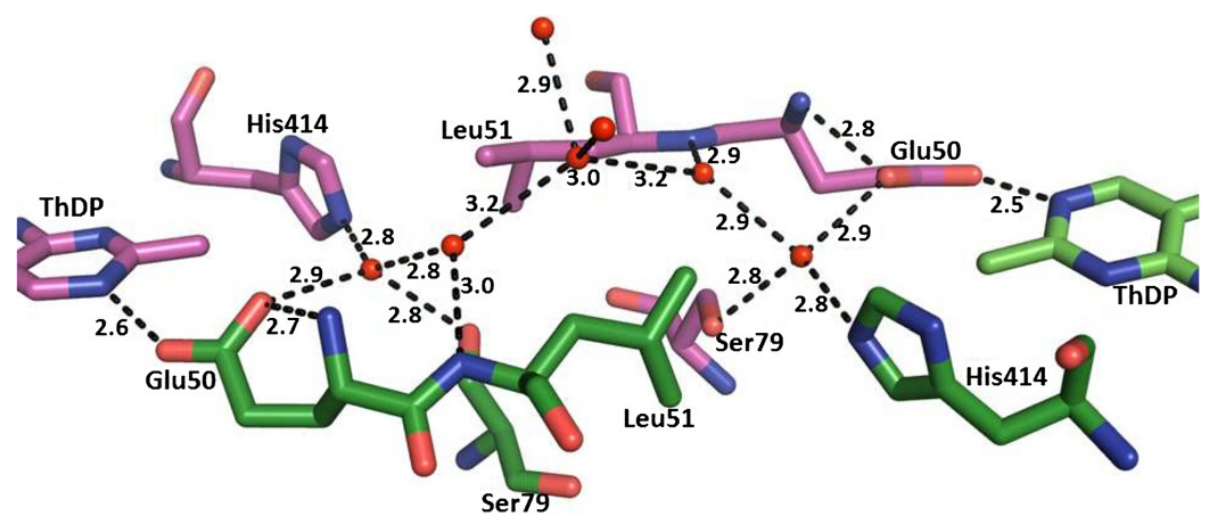

Figure 5 Model of the water tunnel connecting the two active sites in a GdPDC dimer. Water molecules are shown as red spheres. Residues lining the water tunnel are shown as stick models in dark green and labeled. The carbon atoms in the pyrimidine rings of the ThDP cofactor molecules are colored red and nitrogen in blue.

other Gram negative PDCs with regards to substrate recognition and decarboxylation, showing a preference for short-chain aliphatic 2-keto acids [36]. The significantly higher $k_{\text {cat }} / K_{M}$ for pyruvate compared with the nearest analogues 2-ketobutanoate and 2-ketopentanoate, and the retention of Ile468, proposedly crucial for substrate specificity, implies that this enzyme favors pyruvate as its physiological substrate. It can hence be considered a bona fide pyruvate decarboxylase [36,37]. Furthermore, as GdPDC does not have any detectable activity on indole-3pyruvate, it may be ruled out as a contributor to IAA production in G. diazotrophicus PAL5.

The $\mathrm{pH}$ dependence of $K_{M}$ and therefore $k_{c a t} / K_{M}$ for this class of enzymes is well documented $[5,26,49,50]$. GdPDC appears to behave in much the same way as its Gram-negative counterparts in terms of kinetic behavior, displaying the same $\mathrm{pH}$ dependence of $K_{M}$, with a 20 -fold improvement from $\mathrm{pH} 7$ to $\mathrm{pH} 5$, while catalytic efficiency remains largely the same due to only a small change in $k_{\text {cat }}$ ( 2 fold) over the same $\mathrm{pH}$ range (Table 1 ). Although the minimum specific activity for GdPDC with pyruvate as substrate, is nine times lower compared with the maximum specific activity reported for ZmPDC, the lower $K_{M}$ at $\mathrm{pH} 5$ means that the catalytic efficiency $\left(k_{\text {cat }} / K_{M}\right)$ at this $\mathrm{pH}$ is comparable to the highest reported values for ZmPDC (Table 1) [38].

A pH optimum of 5.5 for GdPDC (Figure 2A) is similar to those of other bacterial PDCs, and also agrees with the $\mathrm{pH}$ optimum for growth of its host [51,52]. G. diazotrophicus is an obligate sugarcane endosymbiont which grows optimally at $\mathrm{pH} 5.5$, which is also the $\mathrm{pH}$ of sugarcane sap [53]. It seems possible therefore that the GdPDC has evolved to perform best at the physiological $\mathrm{pH}$ of the plant sap environment. Whether the G. diazotrophicus intracellular $\mathrm{pH}$ is similar to that of the sugarcane sap is yet to be determined. However, it has been shown that for other aerobic acetogenic bacteria, such as Acetobacter aceti, they are unable to maintain an internal $\mathrm{pH}$ above that of its external environment resulting in an acidic intracellular environment [54]. Perhaps a similar scenario is true for G. diazotrophicus, applying selective pressure for the PDC to perform at this physiological $\mathrm{pH}$ [55]. There are only four other characterized enzymes from G. diazotrophicus. One of these is a secreted levansucrase which has an optimal $\mathrm{pH}$ at 5 , while the other two enzymes, a membrane bound alcohol dehydrogenase has an optimum of 6 and a nitrogenase at pH6 [56]. It has also been shown that plant PDC expression is induced in response to lowered $\mathrm{pH}$ caused by oxygen stress $[57,58]$. In G. diazotrophicus the $p d c$ is divergently transcribed from a LysR-like regulator with 98 bp between the translational start of both genes, suggesting that $p d c$ expression is regulated and is not constitutively expressed. It would therefore be of interest to determine if expression of GdPDC is also $\mathrm{pH}$ or oxygen dependent. If G. diazotrophicus, however; does not maintain an acidic intracellular environment, then the optimum $\mathrm{pH}$ could suggest the possibility that the PDC performs a role outside the bacterial cell in support of plant cell metabolism under oxygen stress.

As discussed, the low $K_{M}$ for pyruvate at $\mathrm{pH} 5$ suggests that if it functions mainly at or near this $\mathrm{pH}$, GdPDC would be an extremely good pyruvate scavenger under physiological conditions. The structure of GdPDC aligns well to the related PDCs from A. pasteurianus and $Z$. mobilis with small rmsd's for C $\alpha$ positions indicating high structural conservation for these enzymes. The lower thermostability of GdPDC [36] is presumably due to the smaller number of hydrogen bonds and salt bridges between monomers compared to the enzymes from $Z$. mobilis and A. pasteurianus [59]. Molecular dynamic studies comparing the structures of the three bacterial PDCs at different temperatures could shed light on the nature of thermostability differences observed [60]. The 
enzyme does not exhibit significant biochemical or structural differences to its Gram negative counterparts, and indicates that there may be strong selective pressure to maintain the biochemical and structural properties of these enzymes in a narrow range across the range of microorganisms it has been identified in. Its reduced thermostability and lower $\mathrm{T}_{\text {opt }}$ likely reflects the physical conditions under which GdPDC has been selected for, resulting from the mesophilic endosymbiotic relationship.

There is obvious biotechnological potential for this class of enzyme in engineering of ethanologenic strains as well as in engineering of transgenic crops capable of surviving adverse conditions [61]. The bacterial enzymes which, apart from the $S$. ventriculi enzyme, are not affected by substrate activation and which have higher thermostabilities and activities compared with their yeast and plant counterparts are particularly attractive. Towards ethanologenesis, the dual function pyruvate ferrodoxin oxidoreductase/pyruvate decarboxylase enzymes from several thermophilic archaea have been described, opening the possibility of using these for thermophilic ethanologenesis. Some of their biochemical characteristics however (low PDC activity, high pH optima and oxygen sensitivity), make them unsuitable for engineering of certain ethanologenic strains that operate under microaerobic conditions (Geobacillus thermoglucosidasius) or low temperature $(S$. cerevisiae) [62]. Considering the rarity of true PDCs and their narrow functionality, it seems unlikely that a thermophilic variant exists in nature. We propose that, as with most industrially used enzymes, the ideal PDC can only be generated through engineering, and perhaps these two groups of enzymes represent good starting points.

A picture is emerging that the organisms containing these enzymes are strongly plant associated, in which the environment contains ethanol and a lowered $\mathrm{pH}$; ideal conditions for the PDC to play a key role in metabolism. The rarity of these enzymes therefore appears to be due to the PDC only being of significant metabolic importance in these environments. However, the small range of niches they occupy also puts selective pressure on them to adopt characteristics that fall in a similarly narrow range. $G$. diazotrophicus is an obligate plant endophyte, shown to fix dinitrogen, produce plant growth hormones and protect plants against pathogens such as Xanthomonas albilineans $[63,64]$. It is expected that the role of the PDC enzyme in G. diazotrophicus is to convert pyruvate to acetaldehyde. However, the reason for doing so (when and why it's expression is turned on), whether it is part of the central metabolic pathways or selectively expressed under altered physiological states, perhaps in support of its symbiotic host, remains to be determined. The metabolic importance of PDCs in acetic acid bacteria has been described for two of the members from this family, A. pasteurianus and G. oxydans. In both cases
PDC plays an important role in oxidative metabolism $[4,16]$. The rarity of bacterial PDCs together with their importance in oxidative metabolism in these bacteria, suggests that the enzyme is retained only as a necessity and not as an accessory function. The retention of the enzyme in G. diazotrophicus therefore implies importance of the enzyme, however perhaps not in oxidative metabolism. Four proteomic studies looking at global and differential gene expression in G. diazotrophicus in pure culture versus when grown in association with sugarcane plantlets did not identify the PDC as an expressed enzyme [65-68]. It could either be that PDC levels are below the detection limit of these experiments, or that the gene is not expressed under the conditions of the experiment (aerobic). It was recently proposed that acetic acid bacteria, although being described as obligate aerobic organisms, have the molecular machinery (ubiquinol oxidases) to enable them to thrive under microaerobic conditions [69]. Although speculative, should the G. diazotrophicus PDC be shown to further help plants cope with oxygen stress, by operating in a fermentative manner, this would further deepen the symbiotic relationship between these two organisms to the point where G. diazotrophicus could almost be considered a "plant organelle".

\section{Conclusions}

Understanding the various roles that pyruvate decarboxylases play in their hosts is of importance not only from a fundamental biology point of view, but as is the case with G. diazotrophicus, perhaps also of economic importance. Here we show the enzyme from G. diazotrophicus is very similar to those from other Gram negative bacterial hosts, however what role it plays in this host remains to be elucidated. This study opens the door to further exploration of the role the enzyme plays in its host as well as contributing to our knowledge of these rare enzymes.

\section{Methods}

Media, bacterial strains and plasmids

Bacterial strains and plasmids used in this study are listed in Table 3. E. coli strains were grown in Lysogeny broth (LB) with either ampicillin $(200 \mu \mathrm{g} / \mathrm{ml})$ or kanamycin $(50 \mu \mathrm{g} / \mathrm{ml})$ as required. G. diazotrophicus was cultured in medium containing, per liter: $5 \mathrm{~g}$ yeast extract, $3 \mathrm{~g}$ peptone, $25 \mathrm{~g}$ mannitol. All reagents were purchased from Merck. Cultures were incubated at $30^{\circ} \mathrm{C}$.

\section{DNA manipulations and sequencing}

Plasmid preparation, restriction endonuclease digestion, gel electrophoresis, ligation and Southern/colony blot hybridization were performed using standard methods or manufacturers' recommendations [70]. Ultrapure plasmid DNA was obtained using the Wizard Plus SV miniprep DNA purification system (Promega ${ }^{\mathrm{\tau \mu}}$ ). Total DNA from all 
Table 3 Bacterial strains, plasmids and primers used in this study

\begin{tabular}{|c|c|c|}
\hline Strain or plasmid & Genotype or description & Source or reference \\
\hline \multicolumn{3}{|l|}{ Strains } \\
\hline G. diazotrophicus ATCC 49037 & Wild type strain PAI 5 & American type culture collection \\
\hline E. coli DH5a & $\begin{array}{l}\left.\mathrm{F}^{\prime} \text { lendA1 hsdR17 ( } \mathrm{r}_{\mathrm{K}}^{-} \mathrm{m}_{\mathrm{K}}^{+}\right) \text {supE44 thi-1 reacA1 gyrA } \\
\left(\mathrm{Nal} \mathrm{l}^{\prime}\right) \text { relA1 } \Delta(\text { lacZYA-argF)U169 ( } 980 \mathrm{dlac} \Delta(\text { lacZ)M15) }\end{array}$ & Promega Corp. \\
\hline E. coli BL21-DE3 & E. coli B F ${ }^{-} d c m$ omp $T^{\top} h s d S\left(r_{B}^{-} m_{B}^{-}\right)$gal $\lambda(D E 3)$ & Invitrogen Corp. \\
\hline \multicolumn{3}{|l|}{ Plasmids } \\
\hline pGEM-T & $A p^{r}$; T-tailed PCR product cloning vector & Promega Corp. \\
\hline pET17b & Ap ${ }^{r}$; ColE1 replicon, HIS-tag expression vector & Novagen Corp. \\
\hline pET28a & Kan'; ColE1 replicon, HIS-tag expression vector & Novagen Corp. \\
\hline pGD & Kan'; ColE1 replicon; G. diazatrophicus pdc gene cloned into pET28a & This study \\
\hline \multicolumn{3}{|l|}{ Primers } \\
\hline GDPDCpETF & 5'-GGAATTCCATATGACCTATACCGTTGGACG-3' & This study \\
\hline GDPDCpETR & 5'-CCGCTCGAGTCAGCCCGCGCGCGGC-3' & This study \\
\hline GDPDCseq & 5'-ATCGACGCGCTGCTGAGCCC-3' & This study \\
\hline T7 promoter & 5'-TAATACGACTCACTATAGGG-3' & Promega Corp. \\
\hline T7 terminator & 5'-GCTAGTTATTGCTCAGCGG-3' & Promega Corp. \\
\hline
\end{tabular}

Italics sections in primer sequences indicate restriction endonuclease sites.

bacterial strains was prepared as described [71]. The QIAGEN plasmid midi kit was used for large-scale plasmid preparations. DNA was sequenced using an ABI Prism 377 automated DNA sequencer and sequences were analyzed with DNAMAN (version 4.1, Lynnon BioSoft). Full length PDC protein sequences were aligned using the full alignment feature of DNAMAN, and the neighbor-joining tree [72] constructed using MEGA6 [73].

\section{Polymerase chain reaction (PCR)}

PCR amplifications were performed using KAPA2G Robust DNA polymerase (KAPA BIOSYSTEMS ${ }^{\mathrm{m}}$ ). Generally, $50 \mathrm{ng}$ DNA were used in a $50 \mu \mathrm{l}$ reaction volume containing $2 \mathrm{mM} \mathrm{MgCl}_{2}, 0.125 \mu \mathrm{M}$ of each primer, $0.2 \mathrm{mM}$ of each deoxynucleoside triphosphate, and $1 \mathrm{U}$ DNA polymerase. Reactions were carried out in a Hybaid Sprint thermocycler, with initial denaturation for $60 \mathrm{~s}$ at $94^{\circ} \mathrm{C}$, followed by 30 cycles of denaturation $\left(30 \mathrm{~s}, 94^{\circ} \mathrm{C}\right)$, annealing $(30 \mathrm{~s})$ and variable elongation $\left(72^{\circ} \mathrm{C}\right)$, where annealing temperatures and elongation times were adjusted as required. Primers are also listed in Table 3.

\section{Cloning of the G. diazotrophicus pdc}

The $p d c$ gene from G. diazotrophicus (Genbank accession number: KJ746104) was identified by BLASTn search of the genome of this species, using the Z. mobilis $p d c$ sequence as a comparator. Primers were designed for its amplification, amplified using Robust DNA polymerase (no 3'-5' exonuclease activity), and cloned into pGEM-T Easy (Promega). To generate an error-free construct, two fragments from two different clones were subcloned into pET17b to reconstruct the original gene. Briefly, the 5'
1320 bp NdeI-PvuII fragment, and the 3' 357 bp PvuII-XhoI fragment were cloned into pET17b separately, using the SpeI (sites in pGEM-T Easy and pET17b) and PvuII (sites in the gene, position $1320 \mathrm{bp}$, and in pET17b) to clone the 5' fragment into pET17b. The 3' $\sim 560$ bp PvuII-PvuII (second $P v u I I$ site from pGEM-T Easy vector) fragment was cloned into the pET17b construct using the sole $P v u I I$ site. The correct orientation was confirmed by restriction digest with $P v u$ I. The gene was subcloned in pET28a using the NdeI and XhoI sites, resulting in construct pGD. The final sequence was confirmed as representative of the original gene using primers specific to the $\mathrm{T} 7$ promoter, $\mathrm{T} 7$ terminator and an internal primer (GDPDCseq).

\section{Purification of PDC protein}

An overnight culture of pGD in E. coli BL21-DE3 with kanamycin $(50 \mu \mathrm{g} / \mathrm{ml})$ was used to inoculate fresh LB (1\% transfer) and incubated overnight at room temperature with aeration $(120 \mathrm{rpm})$ to produce GdPDC without IPTG induction. The cells were collected by centrifugation $(3000 \times \mathrm{g}$ for $10 \mathrm{~min})$ and lysed with BugBuster $^{\text {Tix }}$. The suspension was incubated at room temperature for $20 \mathrm{~min}$ with shaking. After cell debris removal by centrifugation $(7840 \times \mathrm{g}, 20 \mathrm{~min})$, DNaseI and RNaseA (Fermentas) were added $(10 \mathrm{U} / \mathrm{ml})$ to reduce lysate viscosity and the solution incubated at room temperature with shaking for $30 \mathrm{~min}^{\text {. HisBind }}{ }^{\mathrm{Tw}}$ resin and buffer kit (Novagen) were used to purify the protein. After elution with $9 \mathrm{ml}$ of $250 \mathrm{mM}$ imidazole buffer (1 $\mathrm{M}$ imidazole, $0.5 \mathrm{M} \mathrm{NaCl}, 20 \mathrm{mM}$ Tris- $\mathrm{HCl} \mathrm{pH}$ 7.9), the protein was dialyzed against 200 volumes of $200 \mathrm{mM}$ sodium citrate $\mathrm{pH}$ 6.0, $1 \mathrm{mM}$ ThDP and $1 \mathrm{mM} \mathrm{MgCl}_{2}$. 
The purity was estimated by reducing SDS-PAGE gel (12\%) and protein concentrations determined using Bradford reagent (Bio-Rad) with bovine serum albumin as the standard ([74]; Figure 1).

\section{Crystallization and structure determination}

Following Ni-NTA/His ${ }_{6}$-tag affinity chromatography purification the protein was concentrated to $\pm 4 \mathrm{mg} / \mathrm{ml}$ by ultrafiltration using a Vivaspin 20 column (Sartorius). Crystals grew at $25^{\circ} \mathrm{C}$ without further additives. For cryoprotection $30 \%(\mathrm{v} / \mathrm{v})$ glycerol was added. X-ray diffraction data was collected at beamline Proxima 1, Soleil Synchrotron, St. Aubin, France at $100 \mathrm{~K}$. Indexing, space group assignment and data integration were performed using iMosflm [75], while data were scaled and merged using SCALA [76]. All further data manipulations were performed using the CCP4 package [77]. MOLREP [78] was used for molecular replacement using 2VBI as molecular model. REFMAC5 was used for structure refinement [79], Coot for graphical model building [80], WHATIF for model validation [81] and PyMOL for molecular depictions (Delano Scientific). The align feature in PyMol was used for structure alignments. The root mean square deviation (rmsd) between two models is calculated using $\left(\left(\sum\left(\mathrm{d}_{\mathrm{ii}}\right)^{2}\right) / \mathrm{N}\right)^{1 / 2}$, where $\mathrm{d}_{\mathrm{ii}}$ is the distance between the $i^{\text {th }}$ atom of structure 1 and the $i^{\text {th }}$ atom of structure 2 , and $\mathrm{N}$ is the number of matched atoms. The interface area was calculated and residues in monomermonomer interfaces identified using the PDBePISA online server (http://tinyurl.com/35w8z7). PDB code 4cok has been assigned to the structure.

\section{Steady state kinetic analysis and determination of substrate range}

PDC activity was measured using a coupled assay with baker's yeast ADH (Sigma-Aldrich) as described previously [82]. The reaction mixture ( $1 \mathrm{ml}$ final volume) contained $0.25 \mathrm{mM} \mathrm{NADH}, 5 \mathrm{mM} \mathrm{MgCl}_{2}, 0.1 \mathrm{mM}$ ThDP, $5 \mathrm{mM}$ pyruvate (unless stated otherwise) and $10 \mathrm{U}$ of $\mathrm{ADH}$ in $50 \mathrm{mM}$ MES or $200 \mathrm{mM}$ Na citrate buffers, $\mathrm{pH} 6.4$ or 6.0 respectively. For substrate range determination, $\mathrm{ADH}$ was replaced with $1 \mathrm{U} / \mathrm{ml}$ baker's yeast aldehyde dehydrogenase (ALDH, Sigma-Aldrich) when testing 2-ketobutanoate, 2-ketopentanoate, 2-keto-4-methylpentanoate, 3-phenyl2 -oxopropanoate. $\beta$-mercaptoethanol was added to a final concentration of $3 \mathrm{mM}$ and $\mathrm{NADH}$ replaced with $\mathrm{NAD}^{+}$. Assays were performed in $100 \mathrm{mM}$ citric acid/ $\mathrm{K}_{2} \mathrm{HPO}_{4}$ buffer, pH 7 [83]. Activities were recorded at $25^{\circ} \mathrm{C}$ unless otherwise indicated, using a Cary 50 temperature controlled spectrophotometer (Varian). To determine enzyme activity for benzoyl formate, 3-hydroxy-phenyl pyruvate and indole-3-pyruvate HPLC assays were employed. Reactions were run on a Hypersil Gold C18 $250 \times 4.6 \mathrm{~mm}$ (Thermo Scientific) on a Dionex Ultimate 3000 machine, using 30\% MeOH/1\% Acetic acid mobile phase as mobile phase under isocratic elution $\left(1 \mathrm{ml} / \mathrm{min}, 40^{\circ} \mathrm{C}\right)$. Twenty $\mu \mathrm{l}$ of each sample was injected by autosampler and the components detected using either a refractive index detector or a UV/Vis photodiode array at $245 \mathrm{~nm}$. To generate kinetic data, initial enzyme velocities were determined over the substrate range $0.1 \mathrm{mM}$ to $30 \mathrm{mM}$ for pyruvate or $24 \mathrm{mM}$ for other 2-keto acids. Kinetic parameters were determined by non-linear data fitting to hyperbolic curves (GraphPad Prism v. 4.00, GraphPad Software, San Diego, CA, USA). $k_{\text {cat }}$ values were calculated based on the MW of the tetramer $(240 \mathrm{kDa})$ with four active site.

\section{Availability of supporting data}

Supporting data are included as Additional file 1: Figure S1, Additional file 2: Figure S2 and Additional file 3: Figure S3.

\section{Additional files}

\begin{abstract}
Additional file 1: Figure S1. Multiple sequence alignment of selected PDC protein sequences generated using DNAman (Lynnon BioSoft). GdiPDC - G. diazotrophicus (KJ746104); GoxPDC - G. oxydans (KF650839); ApaPDC Acetobacter pasteurianus (AF368435.1); ZpaPDC - Z. palmae (AF474145); ZmoPDC - Z. mobilis (AB359063); ZmaPDC - Z. mays (X17555); ScePDC - S. cerevisiae (X04675); SvePDC - S. ventriculi (AF354297); Lyngbya aestuarii (WP023067698); Acidomonas methanolica (GAJ29946); Acetobacter pomorum (WP006115789); Acetobacter aceti (WP010667855); Microcystis aeruginosa (WP_0027648); Moorea producens (WP008180762); Microbulbifer variabilis (WP020414286); Legionella pneumophila (YP006505162); MDM (CBI10829); Ktedonobacter racemifer (WP007922190); Komagataeibacter oboediens (WP010515737); Komagataeibacter hansenii (WP003622049); Komagataeibacter europaeus (WP010509054); Granulicella tundricola (YP004210504); Gluconobacter thailandicus (WP007283613); Gluconobacter morbifer (WP008852112); Gluconobacter frateurii (WP023941876); Gluconacetobacter xylinus (AHI26557); Gluconacetobacter medellinensis (YP004868149); Fluoribacter dumoffii (WP010654974); Enterobacter cloacae iPDC (P23234); Commensalibacter intestini (WP008853550); Beijerinckia indica (YP001834435); Pseudomonas putida BFD (YP008115845); MDMMine Drainage Metagenome (CBI10829.1). Residues shaded in black are conserved, those in dark grey to $75 \%$, and those in light grey to $50 \%$. The conserved ThDP-binding motif is marked by a solid line, ThDP binding residues by triangles, $\mathrm{Mg}^{2+}$-binding residues by arrows, catalytic pocket residues probably involved in catalysis by circles. An asterisk indicates lle468 involved in substrate specificity, while a star highlights Ile472 proposed to be involved in substrate positioning. Two squares mark Arg221 located at the same position as Cys221 ScePDC and SvePDC involved in substrate activation.
\end{abstract}

Additional file 2: Figure S2. A denaturing SDS-PAGE gel showing purified GdiPDC. Lane 1, Molecular weight marker (Fermentas), Lane 2, Ni-NTA purified GdiPDC-His fusion protein. GdiPDC has a mass of $\sim 59 \mathrm{kDa}$ but runs at a slightly smaller size.

Additional file 3: Figure S3. Orthorhombic crystals of GdiPDC. The scale bar indicates $50 \mu \mathrm{m}$.

\section{Competing interests}

The authors declare that they have no competing interests.

\section{Authors' contributions}

LVZ performed cloning, purification of the protein, crystallization, sequence alignment, phylogenetic tree construction. WDS collected X-ray data. WDS and LVZ solved and refined the crystal structure. DAC and MIT conceived the study and participated in its design and coordination. All authors participated in preparing the final manuscript. All authors read and approved the final manuscript. 


\section{Acknowledgement}

This work was supported by the National Research Foundation of South Africa.

\section{Author details}

${ }^{1}$ Institute for Microbial Biotechnology and Metagenomics (IMBM), University of the Western Cape, Robert Sobukwe Road, Bellville, Cape Town, South Africa. ${ }^{2}$ Department of Biochemistry, University of Pretoria, 2 Lynnwood Road, Pretoria 0002, South Africa. ${ }^{3}$ Department of Genetics, University of Pretoria, Pretoria 0002 , South Africa.

Received: 8 July 2014 Accepted: 25 September 2014

Published online: 05 November 2014

\section{References}

1. Lee K, Jeong C, An YJ, Lee H, Park S, Seok Y, Kim P, Lee J, Lee K, Cha S: FrsA functions as a cofactor-independent decarboxylase to control metabolic flux. Nat Chem Biol 2011, 7:434-436.

2. Kellett WF, Brunk E, Desai BJ, Fedorov AA, Almo SC, Gerlt JA, Rothlisberger U, Richards NGJ: Computational, Structural, and Kinetic Evidence That Vibrio vulnificus FrsA Is Not a Cofactor-Independent Pyruvate Decarboxylase. Biochem 2013, 52:1842-1844.

3. King TE, Cheldelin VH: Pyruvic carboxylase of Acetobacter suboxydans. J Biol Chem 1954, 208:821-831.

4. Raj KC, Ingram LO, Maupin-Furlow JA: Pyruvate decarboxylase: a key enzyme for the oxidative metabolism of lactic acid by Acetobacter pasteurianus. Arch Microbiol 2001, 176:443-451.

5. Raj KC, Talarico LA, Ingram LO, Maupin-Furlow JA: Cloning and characterization of the Zymobacter palmae pyruvate decarboxylase gene (pdc) and comparison to bacterial homologues. Appl Environ Microbiol 2002, 686:2869-2876.

6. Lowe SE, Zeikus JG: Purification and characterization of pyruvate decarboxylase from Sarcina ventriculi. J Gen Microbiol 1992, 138:803-807.

7. Van Zyl $\sqcup$, Taylor MP, Eley K, Tuffin M, Cowan DA: Engineering pyruvate decarboxylase-mediated ethanol production in the thermophilic host Geobacillus thermoglucosidasius. Appl Microbiol Biotechnol 2013, 98:1247-1259.

8. Candy JM, Duggleby RG: Structure and properties of pyruvate decarboxylase and site directed mutagenesis of the Zymomonas mobilis enzyme. Biochim Biophys Acta 1998, 1385:323-338.

9. Gold RS, Meagher MM, Tong S, Hutkins RW, Conway T: Cloning and expression of the Zymomonas mobilis "production of ethanol" genes in Lactobacillus casei. Curr Microbiol 1996, 33:256-260.

10. Bongers RS, Hoefnagel MH, Kleerebezem M: High-level acetaldehyde production in Lactococcus lactis by metabolic engineering. Appl Environ Microbiol 2005, 71:1109-1113.

11. Kaczowka SJ, Reuter CJ, Talarico LA, Maupin-Furlow JA: Recombinant production of Zymomonas mobilis pyruvate decarboxylase in the haloarchaeon Haloferax volcanii. Archaea 2005, 15:327-334.

12. Liu S, Dien BS, Cotta MA: Functional expression of bacterial Zymobacter palmae pyruvate decarboxylase gene in Lactococcus lactis. Curr Microbiol 2005, 50:324-328.

13. Talarico LA, Gil MA, Yomano LP, Ingram LO, Maupin-Furlow JA: Construction and expression of an ethanol production operon in Gram-positive bacteria. Microbiol 2005, 151:4023-4031.

14. Liu S, Dien BS, Nichols NN, Bischoff KM, Hughes SR, Cotta MA: Coexpression of pyruvate decarboxylase and alcohol dehydrogenase genes in Lactobacillus brevis. FEMS Microbiol Lett 2007, 274:291-297.

15. Talarico LA, Ingram LO, Maupin-Furlow JA: Production of the Grampositive Sarcina ventriculi pyruvate decarboxylase in Escherichia coli. Microbiol 2001, 147:2425-2435.

16. Peters B, Junker A, Brauer K, Mühlthaler B, Kostner D, Mientus M, Liebl W, Ehrenreich A: Deletion of pyruvate decarboxylase by a new method for efficient markerless gene deletions in Gluconobacter oxydans. Appl Microbiol Biotechnol 2012, 97:2521-2530.

17. Meyer D, Neumann P, Ficner R, Tittmann K: Observation of a stable carbene at the active site of a thiamin enzyme. Nat Chem Biol 2013, 9:488-490.

18. Kern D, Kern G, Neef H, Tittmann K, Killenberg-Jabs M, Wikner C, Schneider $\mathrm{G}$, Hubner G: How thiamine diphosphate is activated in enzymes. Science 1997, 275:67-70.

19. Zhang S, Liu M, Yan Y, Zhang Z, Jordan F: C2-alpha-lactylthiamin diphosphate is an intermediate on the pathway of thiamin diphosphate- dependent pyruvate decarboxylation. Evidence on enzymes and models. J Biol Chem 2004, 279:54312-54318.

20. Baykal AT, Kakalis L, Jordan F: Electronic and nuclear magnetic resonance spectroscopic features of the 1',4'-iminopyrimidine tautomeric form of thiamin diphosphate, a novel intermediate on enzymes requiring this coenzyme. Biochem 2006, 4524:7522-7528.

21. Lie MA, Celik L, Jorgensen KA, Schiott B: Cofactor activation and substrate binding in pyruvate decarboxylase. Insights into the reaction mechanism from molecular dynamics simulations. Biochem 2005, 4445:14792-14806.

22. Pei $X Y$, Erixon KM, Luisi BF, Leeper FJ: Structural insights into the prereaction state of pyruvate decarboxylase from Zymomonas mobilis. Biochem 2010, 498:1727-1736.

23. Brandt GS, Kneen MM, Chakraborty S, Baykal AT, Nemeria N, Yep A, Ruby DI, Petsko GA, Kenyon GL, McLeish MJ, Jordan F, Ringe D: Snapshot of a reaction intermediate: analysis of benzoylformate decarboxylase in complex with a benzoylphosphonate inhibitor. Biochem 2009, 4815:3247-3257.

24. Chakraborty S, Nemeria NS, Balakrishnan A, Brandt GS, Kneen MM, Yep A McLeish MJ, Kenyon GL, Petsko GA, Ringe D, Jordan F: Detection and time course of formation of major thiamin diphosphate-bound covalent intermediates derived from a chromophoric substrate analogue on benzoylformate decarboxylase. Biochem 2009, 485:981-994.

25. Nemeria NS, Chakraborty S, Balakrishnan A, Jordan F: Reaction mechanisms of thiamin diphosphate enzymes: defining states of ionization and tautomerization of the cofactor at individual steps. FEBS J 2009, 276:2432-2446.

26. Meyer D, Neumann P, Parthier C, Friedemann R, Nemeria N, Jordan F, Tittmann K: Double duty for a conserved glutamate in pyruvate decarboxylase: evidence of the participation in stereoelectronically controlled decarboxylation and in protonation of the nascent carbanion/ enamine intermediate. Biochem 2010, 49:8197-8212.

27. Dobritzsch D, Konig S, Schneider G, Lu G: High resolution crystal structure of pyruvate decarboxylase from Zymomonas mobilis. Implications for substrate activation in pyruvate decarboxylases. J Biol Chem 1998, 273:20196-20204.

28. Rother D, Kolter G, Gerhards T, Berthold CL, Gauchenova E, Knoll M, Pleiss J, Müller M, Schneider G, Pohl M: S-Selective mixed carboligation by structure-based design of the pyruvate decarboxylase from Acetobacter pasteurianus. Chem Cat Chem 2011, 10:1587-1596.

29. Lee S, Flores-Encarnacion M, Contreras-Zentella M, Garcia-Flores L, Escamilla JE, Kennedy C: Indole-3-acetic acid biosynthesis is deficient in Gluconacetobacter diazotrophicus strains with mutations in cytochrome c biogenesis genes. J Bacteriol 2004, 186:5384-5391.

30. Saravanan VS, Madhaiyan M, Osborne J, Thangaraju M, Sa TM: Ecological occurrence of Gluconacetobacter diazotrophicus and nitrogen-fixing Acetobacteraceae members: their possible role in plant growth promotion. Microb Ecol 2008, 55:130-140.

31. Bertalan M, Albano R, de Padua V, Rouws L, Rojas C, Hemerly A, Teixeira K, Schwab S, Araujo J, Oliveira A, Franca L, Magalhaes V, Alqueres S, Cardoso A, Almeida W, Loureiro MM, Nogueira E, Cidade D, Oliveira D, Simao T, Macedo J, Valadao A, Dreschsel M, Freitas F, Vidal M, Guedes H, Rodrigues E, Meneses C, Brioso P, Pozzer $L$, et al: Complete genome sequence of the sugarcane nitrogen-fixing endophyte Gluconacetobacter diazotrophicus Pal5. BMC Genomics 2009, 10:450.

32. Felsenstein J: Confidence limits on phylogenies: An approach using the bootstrap. Evolution 1985, 39:783-791.

33. Zuckerkandl E, Pauling L: Evolutionary divergence and convergence in proteins. In Evolving Genes and Proteins. Edited by Bryson V, Vogel HJ. New York: Academic Press; 1965:97-166.

34. Chang AK, Nixon PF, Duggleby RG: Effects of deletions at the carboxyl terminus of Zymomonas mobilis pyruvate decarboxylase on the kinetic properties and substrate specificity. Biochem 2000, 3931:9430-9437.

35. König S, Spinka M, Kutter S: Allosteric activation of pyruvate decarboxylases. A never-ending story? J Mol Cat B: Enzymatic 2009, 61:100-110.

36. Gocke D, Graf T, Brosi H, Frindi-Wosch I, Walter L, Müller M, Pohl M: Comparative characterization of thiamin diphosphate-dependent decarboxylases. J Mol Cat B: Enzymatic 2009, 61:30-35.

37. Siegert P, McLeish MJ, Baumann M, Iding H, Kneen MM, Kenyon GL, Pohl M: Exchanging the substrate specificities of pyruvate decarboxylase from Zymomonas mobilis and benzoylformate decarboxylase from Pseudomonas putida. Protein Eng Des Sel 2005, 187:345-357. 
38. Bringer-Meyer S, Schimz K-L, Sahm H: Pyruvate decarboxylase from Zymomonas mobilis. Isolation and partial characterization. Arch Microbiol 1986, 146:105-110.

39. Pohl M, Mesch K, Rodenbrock A, Kula MR: Stability investigations on the pyruvate decarboxylase from Zymomonas mobilis. Biotechnol Appl Biochem 1995, 22:95-105.

40. Lu G, Dobritzsch D, Baumann S, Schneider G, Konig S: The structural basis of substrate activation in yeast pyruvate decarboxylase. A crystallographic and kinetic study. Eur J Biochem 2000, 267:861-868.

41. Arjunan P, Umland T, Dyda F, Swaminathan S, Furey W, Sax M, Farrenkopf B, Gao Y, Zhang D, Jordan F: Crystal structure of the thiamin diphosphatedependent enzyme pyruvate decarboxylase from the yeast Saccharomyces cerevisiae at 2.3 A resolution. J Mol Biol 1996, 2563:590-600.

42. Lu G, Dobritzsch D, Konig S, Schneider G: Novel tetramer assembly of pyruvate decarboxylase from brewer's yeast observed in a new crystal form. FEBS Lett 1997, 403:249-253.

43. Frank RA, Titman CM, Pratap JV, Luisi BF, Perham RN: A molecular switch and proton wire synchronize the active sites in thiamine enzymes. Science 2004, 306:872-876.

44. Couturier M, Roussel A, Rosengren A, Leone P, Stålbrand H, Berrin J-G: Structural and Biochemical Analyses of Glycoside Hydrolase Families 5 and $26 \beta$-(1,4)-Mannanases from Podospora anserina Reveal Differences upon Manno-oligosaccharide Catalysis. J Biol Chem 2013, 288:14624-14635.

45. George RA, Heringa J: An analysis of protein domain linkers: their classification and role in protein folding. Prot Eng 2003, 15:871-879.

46. Poon DKY, Withers SG, Mclntosh LP: Direct Demonstration of the Flexibility of the Glycosylated Proline-Threonine Linker in the Cellulomonas fimi Xylanase Cex through NMR Spectroscopic Analysis. J Biol Chem 2006, 282:2091-2100.

47. Gokhale RS, Khosla C: Role of linkers in communication between protein modules. Curr Opin Chem Biol 2000, 4:22-27.

48. Quigley PM, Korotkov K, Baneyx F, Hol WGJ: A new native EcHsp31 structure suggests a key role of structural flexibility for chaperone function. Protein Sci 2004, 13:269-277.

49. Schenk G, Leeper FJ, England R, Nixon PF, Duggleby RG: The role of His 113 and His114 in pyruvate decarboxylase from Zymomonas mobilis. Eur J Biochem 1997, 248:63-71.

50. Huang CY, Chang AK, Nixon PF, Duggleby RG: Site-directed mutagenesis of the ionizable groups in the active site of Zymomonas mobilis pyruvate decarboxylase: effect on activity and $\mathrm{pH}$ dependence. Eur J Biochem 2001, 268:3558-3565.

51. Eskin N, Vessey K, Tian L: Research Progress and Perspectives of Nitrogen Fixing Bacterium, Gluconacetobacter diazotrophicus, in Monocot Plants. Int J Agron 2014, doi:10.1155/2014/208383.

52. James EK, Olivares FL, de Oliveira ALM, dos Reis FB Jr, Aa Silva LG, Reis VM: Further observations on the interaction between sugar cane and Gluconacetobacter diazotophicus under laboratory and greenhouse conditions. J Exp Bot 2001, 52:747-760.

53. Dong Z, Canny MJ, McCully ME, Roboredo MR, Cabadilla CF, Ortega E, Rodés R: A Nitrogen-Fixing Endophyte of Sugarcane Stems A New Role for the Apoplast. Plant Physiol 1994, 105:1139-1147.

54. Menzel U, Gottschalk G: The internal pH of Acetobacterium wieringae and Acetobater aceti during growth and production of acetic acid. Arch Microbiol 1985, 143:47-51.

55. Talley $\mathrm{K}$, Alexov $\mathrm{E}$ : On the $\mathrm{pH}$-optimum of activity and stability of proteins. Proteins 2010, 78:2699-2706.

56. Gomez-Manzo S, Contreras-Zentella M, Gonzalez-Valdez A, Sosa-Torres M, Arreguin-Espinoza R, Escamilla-Marvan E: The PQQ-alcohol dehydrogenase of Gluconacetobacter diazotrophicus. Int J Food Microbiol 2008, 125:71-78.

57. Kelley PM: Maize PDC mRNA is induced anaerobically. Plant Mol Biol 1989, 13:213-222.

58. Mithran M, Paparelli E, Novi G, Perata P, Loreti E: Analysis of the role of the pyruvate decarboxylase gene family in Arabidopsis thaliana under low-oxygen conditions. Plant Biol 2013, 16:28-34.

59. Bjork A, Dalhus B, Mantzilas D, Sirevag R, Eijsink VG: Large improvement in the thermal stability of a tetrameric malate dehydrogenase by single point mutations at the dimer-dimer interface. J Mol Biol 2004, 3415:1215-1226.

60. Paul M, Hazra M, Barman A, Hazra S: Comparative molecular dynamics simulation studies for determining factors contributing to the thermostability of chemotaxis protein "CheY". J Biomol Struct Dyn 2013, doi:10.1080/07391102.2013.799438.
61. Tadege M, Brändle R, Kuhlemeier C: Anoxia tolerance in tobacco roots: effect of overexpression of pyruvate decarboxylase. Plant J 1998, 14:327-335.

62. Eram MS, Oduaran E, Ma K: The bifunctional pyruvate decarboxylase/ pyruvate ferrodoxin oxidoreductase from Thermococcus guaymasensis. Archaea 2014, doi:10.1155/2014/349379.

63. Arencibia AD, Vinagre F, Estevez Y, Bernal A, Perez J, Cavalcanti J, Santana I, Hemerly AS: Gluconacetobacter diazotrophicus Elicits a Sugarcane Defense Response Against a Pathogenic Bacteria Xanthomonas albilineans. Plant Signal Behav 2006, 1:265-273.

64. Reis VM, Olivares FL, Döbereiner J: Improved methodology for isolation of Acetobacter diazotrophicus and confirmation of its endophytic habitat. World J Microbiol Biotechnol 1994, 10:401-405.

65. dos Santosa MF, de Páduac VLM, de Matos NE, Hemerlyd AS, Domont GB: Proteome of Gluconacetobacter diazotrophicus co-cultivated with sugarcane plantlets. Proteomics 2010, 73:917-931.

66. Lery LMS, Hemerly AS, Nogueira EM, von Krüger WMA, Bisch PM: Quantitative Proteomic Analysis of the Interaction Between the Endophytic Plant-Growth-Promoting Bacterium Gluconacetobacter diazotrophicus and Sugarcane. MPMI 2011, 24:562-576.

67. Lery LMS, von Krüger WMA, Viana FC, Teixeira KRS, Bisch PM: A comparative proteomic analysis of Gluconacetobacter diazotrophicus PAL5 at exponential and stationary phases of cultures in the presence of high and low levels of inorganic nitrogen compound. Biochim Biophys Acta 2008, 1784:1578-1589.

68. Lery LMS, Coelho A, von Kruger WMA, Goncalves MSM, Santos MF, Valente RH, Santos EO, Rocha SLG, Perales J, Domont GB, Teixeira KRS, Bisch PM: Protein expression profile of Gluconacetobacter diazotrophicus PAL5, a sugarcane endophytic plant growth-promoting bacterium. Proteomics 2008, 8:1631-1644.

69. Chouaia B, Gaiarsa S, Crotti E, Comandatore F, Esposti MD, Ricci I, Alma A, Favia G, Bandi C, Daffonchio D: Acetic Acid Bacteria Genomes Reveal Functional Traits for Adaptation to Life in Insect Guts. Genome Biol Evol 2014, 6:912-920.

70. Sambrook J, Fritsch EF, Maniatis T: Molecular Cloning: A Laboratory Manual. NY: Cold Spring Harbour Laboratory Press; 1989.

71. Kotze AA, Tuffin IM, Deane SM, Rawlings DE: Cloning and characterization of the chromosomal arsenic resistance genes from Acidithiobacillus caldus and enhanced arsenic resistance on conjugal transfer of ars genes located on transposon TnAtcArs. Microbiology 2006, 12:3551-3560.

72. Saitou N, Nei M: The neighbor-joining method: A new method for reconstructing phylogenetic trees. Mol Biol Evol 1987, 4:406-425.

73. Tamura K, Stecher G, Peterson D, Filipski A, Kumar S: MEGA6: Molecular Evolutionary Genetics Analysis version 6.0. Mol Biol Evol 2013, 30:2725-2729.

74. Laemmli UK: Cleavage of structural proteins during the assembly of the head of bacteriophage T4. Nature 1970, 227:680-685.

75. Leslie AG: The integration of macromolecular diffraction data. Acta Crystallogr D Biol Crystallogr 2006, 1:48-57.

76. Evans P: Scaling and assessment of data quality. Acta Crystallogr D Biol Crystallogr 2006, 1:72-82.

77. Potterton E, Briggs $P$, Turkenburg M, Dodson E: A graphical user interface to the CCP4 program suite. Acta Crystallogr D Biol Crystallogr 2003, 7:1131-1137.

78. Vagin A, Teplyakov A: MOLREP: an Automated Program for Molecular Replacement. J Appl Cryst 1997, 30:1022-1025

79. Murshudov GN, Pavol Skubák P, Lebedev AA, Pannu NS, Steiner RA, Nicholls RA, Winn MD, Long F, Vagin AA: REFMAC5 for the refinement of macromolecular crystal structures. Acta Crystallogr D Biol Crystallogr 2011, 67:355-367.

80. Emsley P, Lohkamp B, Scott WG, Cowtan K: Features and development of Coot. Acta Crystallogr D Biol Crystallogr 2010, 66:486-501.

81. Vriend G: WHAT IF: a molecular modeling and drug design program. J Mol Graph 1990, 8:52-56.

82. Holzer H, Schultz G, Villar-Palasi C, Juntgen-Sell J: Isolierungder Hefecarboxylase und Untersuchung uher die Aktivität des Enzyms in lebenden Zellen. Biochem Z 1956, 327:331-344.

83. Vuralhan Z, Luttik MA, Tai SL, Boer VM, Morais MA, Schipper D, Almering MJ, Kotter P, Dickinson JR, Daran JM, Pronk JT: Physiological characterization of the ARO10-dependent, broad-substrate-specificity 2-oxo acid decarboxylase activity of Saccharomyces cerevisiae. Appl Environ Microbiol 2005, 71:3276-3284.

\section{doi:10.1186/s12900-014-0021-1}

Cite this article as: van Zyl et al: Structure and functional characterization of pyruvate decarboxylase from Gluconacetobacter diazotrophicus. BMC Structural Biology 2014 14:21. 